\title{
Inspiring Design: The Use of Photo Elicitation and Lomography in Gaining the Child's Perspective
}

\author{
Lynne Hall, Susan Jones, Marc Hall, Joanne Richardson, John Hodgson \\ University of Sunderland \\ $+44(0) 191515\{3249,3863,2766,2766,2766\}$ \\ \{lynne.hall, susan.jones, marc.hall\}@sunderland.ac.uk \\ \{Jo_r1984, flangehodge\}@hotmail.com
}

\begin{abstract}
This paper reports on a case study of a participatory technique that focuses on gathering contextual information from users to assist the analysis and design process. It presents a participatory methodology based upon a photo-elicitation approach combined with Lomo photography practices and group-centric analysis aimed at children and teenagers in order to draw together design requirements specifically for them. The paper discusses the use of this approach for designing a multimedia learning application on water safety aimed at 11-13 year olds, with results highlighting the benefits of this approach for creating appropriate designs.
\end{abstract}

\section{Categories and Subject Descriptors}

H5.2 [Information Interfaces and Presentation, e.g., HCI]: User interfaces - user-centred design, theory and methods, graphical user interfaces.

\section{General Terms}

Design, Human Factors.

\section{Keywords}

Participatory design, lomography, photo-elicitation, contextual information, multimedia, interaction design with teenagers and children.

\section{INTRODUCTION}

Multimedia-analysis and design practices have long focused on user-centred design, and have evolved to include participatory approaches that allow design features to become established much earlier and to be better understood. Designing for children presents a particular challenge [5], and research highlights the need for approaches that are not only participatory, but also child-centred, reflecting children's interests and activities [10,31].

Banister and Booth [2] found that children can be incredibly keen, able and ultimately useful participants. Although there has been a significant increase in including children within the design process, many products continue to be designed with

(C) Lynne Hall, Susan Jones, Marc Hall, Joanne Richardson, John Hodgson, 2007

Published by the British Computer Society

People and Computers XXI-HCI... but not as we know it:

Proceedings of HCI 2007

Linden J. Ball, M. Angela Sasse, Corina Sas, Thomas C. Ormerod, Alan

Dix, Peter Bagnall, and Tom McEwan (Editors) only minimal child input. This is predominantly due to the stereotyping that "interviewing children is seen as too problematic" and "children are commonly believed to lack the communication, cognitive and social skills that are the prerequisite of good respondents" [5]; however, "children's role as consumers and citizens is being taken increasingly seriously in the economy, in law and in social policy" [28] and consequently the role of children in product creation deserves similar consideration.

More traditional approaches, such as questionnaires, observation and focus groups make eliciting requirements from children difficult and may not yield accurate or usable results due to language barriers [28], power imbalance [3, 15], and group dynamics [5, 22]. Participatory approaches have particular appeal for children and teenagers, with hands-on experiences encouraging enthusiasm [17,23] and successful participation [43], thereby facilitating insights into children's perspectives, interests and observations [40].

There is considerable potential for the use of visual methods such as photographs, videos and drawings for participatory design. The use of photography for gaining an understanding of users, replaces field notes as data for analysis and provides a medium for dialogue in interviews [24]. However, visual methods of data collection have yet to be fully explored, with visual data receiving relatively little attention in any field [34]. Hurworth [21] notes that "in comparison with other data collection methods, only a relatively small amount has been written concerning the use of the visual medium for research, and even less about how photographs can be integrated into the interviewing process".

It is clear that the analysis and interpretation of visual material, such as photographs, can present particular problems in a research context, particularly in terms of how to verbalise and report on the outputs of visual data collection methods. However, there is an intrinsic value in photographic content generated by users which can effectively be fed into the design process, without the specific need for complex and largely unnecessary visual data analysis. Further, with the gradual shift from text based to media based communication, the collection and distribution of visual material by individuals has risen exponentially, and methods which take a visual approach are in keeping with current trends in human communication.

Not surprisingly, these changing trends are reflected in the use of photographic methods in contextual research methods in particular, for example, cultural probes have incorporated cameras $[8,44]$ as have diary methods [4]. Our work replicating cultural probes and diaries highlighted that children were particularly keen to use personal technology, such as cameras to provide information about their lives, views and interests. Involving the user in the design process through photography 
and subsequent interviews has been successfully used with children [6, 42]. Photography clearly provides a valuable participatory method for accessing children's immediate and detailed perceptions and further, is an ideal methodology with which to engage young people, fitting in as it does with the ways in which children and young people already use and enjoy new technologies.

Internet-based media-sharing networks are flourishing. Different networks offer differing levels of presence depending on how the user can forge their own homepage. Image sharing through web based photo albums is a basic function of such networks. Flickr (www.flickr.com), for example, is an image database designed for users to store and share photos [20]. MySpace (www.myspace.com) is becoming the standard for general internet users to create a web presence, with one of its central functions being image sharing. The popularity and impact of image sharing, especially with children, has been anticipated for years [29]. This situation is fed by the standardization of camera phones in the population [26].

In the majority of photo-elicitation research, users are provided with a structured experience, having to take a number of specific photos or specified items. However, here we describe an approach that has more in common with the more flexible 'probing' approaches such as cultural probes [13] and phone / video diaries [33] which allow the user to choose what to record and present.

In this paper, we discuss the use of a novel and emerging photographic approach called Lomography, which, in contrast to more formal photographic paradigms, "encourages spontaneity, close-ups, ubiquity, and randomness" and "revolves around capturing their [the user's] environment in the here and now" [41]. Lomography is particularly appropriate for children and teenagers, as it requires little skill or competence, largely ignoring well established photographic techniques in favour of an impromptu "shooting from the hip" approach. Lomography is particularly appropriate as a means of photoelicitation, as it encourages the photographer to be spontaneous and to capture pictures of objects, people and scenes - whatever attracts their attention. Understanding and interpreting the images was achieved through the adaptation and extension of existing photo-elicitation techniques to enable the elicitation of views about the cultural and social dimensions of a child's existence. Our aim with this use of Lomography and photoelicitation was to involve children aged 11 to 13 in practical, participatory activities. Through this we hoped to gain insights into their perspectives, interests and observations whilst connecting and engaging with the user group in order to understand them better. In parallel, we aimed to collect and understand the relevance of photographic content that could feed into, and be exploited for, the visual design of a multimedia learning application on water safety.

This paper will explore the background and development of a novel approach which taps into current trends in visual communication among children and young people and emerging photographic approaches to capture multimedia design requirements for users. In particular, the paper will discuss the background to Lomography, how this was used to extend the photo-elicitation method, and how this method was tailored to the user's classroom context. A full account of the method will be reviewed, and outcomes discussed with particular reference to how the process that was developed inspired user interface design of the water-safety product.

\section{USING PHOTOGRAPHY TO INSPIRE DESIGN}

Our research focus is on optimizing the involvement of primary users and stakeholders, children and teachers, in the design and development process of educational technology. Our aim is to develop a classroom-based, curriculum-focused participatory design approach. This innovative approach will have the child as the informant and will aim to match children's expectations of the classroom context reflecting the adult-child dynamic. Our research aims to map curricula objectives and learning outcomes to classroom-based informant activities within the educational software development lifecycle. This research is highly innovative, responding to the recognised need for a classroom-based participatory design approach that takes the curricula needs of teachers and pupils into account.

Here, we focus on the use of photography as a means with which to explore children's views and perspectives. This is in keeping with current trends in visual communication and the use of communications technologies by children and young people. The following sections outline the activities identified in Figure 1, providing background and rationale for our approach.

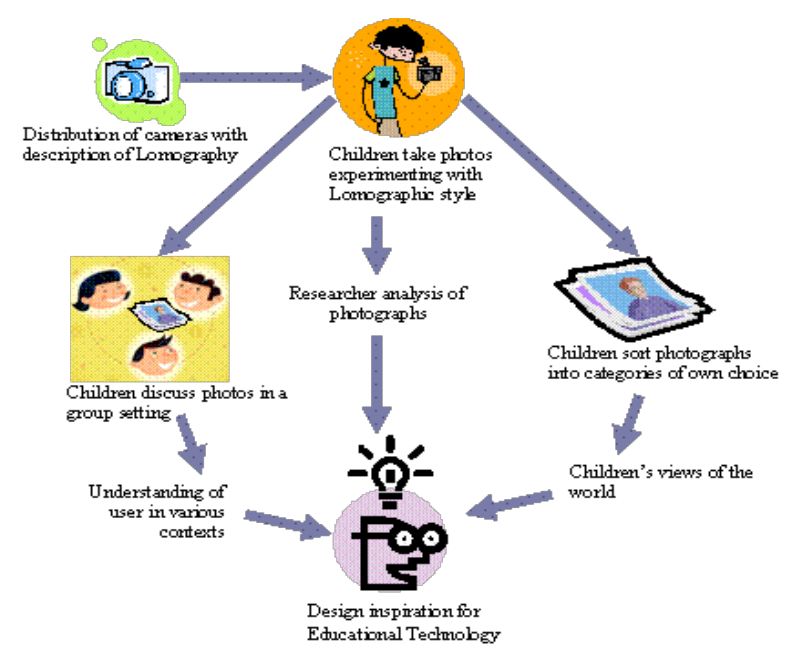

Figure 1. Using photography as design inspiration.

\subsection{Capturing the Context: Lomography}

Since its invention, photography and photographs have become a powerful medium for documenting and changing the human experience. Socially, photographs have been used to mark key events in life, and are used a means of remembering past events. Photographs are used as visual inventories of objects, people, and artifacts and can provide intimate dimensions of social reality. This relates not only to groups, but additionally images that connect a person to society, culture, or history [18]. Indeed, since its inception, documentary photography has been used to highlight social injustice and promote change and continues to do so. Photographs not only have greater ability than text and speech alone to convey experience, but additionally, "have the potential to liberate our thinking and provide us with concepts" [1].

Photography practice is very broad ranging and takes account of particular types of photography and the technologies involved. Photographers, whatever their background, generally set out to take 'good' photographs that have sound composition 
and make appropriate use of cameras and available lighting. However, new, more spontaneous approaches to photography are emerging, which reflect the visual, rather than the textual, as the more prevalent form of communication, and focus more on rapidly capturing experience, than creating carefully constructed and quality photographs through expert technique. These kinds of approaches lend themselves particularly well to visual research methods.

One such novel method of photography which is well suited to gaining a unique insight into the user's context is Lomo photography or 'Lomography'. Lomography is a relatively recent photographic movement, which derives its name from the Lomo camera produced in Russia in the 1980s. The Lomo camera enables the photographer to take rapid, free-form photographs, and is a reaction against the posed compositions that dominate artistic and, increasingly, domestic photographs. The Lomo camera was almost lost and overtaken by newer technology, however, in 1991 the camera and the technique was rediscovered by a group of Viennese students in the Czech Republic. The results these students achieved were "wonderful focused and unfocussed images fresh from life", and the interest in lomography that followed has resulted in exhibitions and societies of Lomography around the world.

Lomography aims to capture everyday experience, for the camera to be continually present, yet not to interfere with the photographer's existence but to enhance it. The rules of Lomography focus on freedom in photographing the environment, shooting from the hip, not posing nor interpreting, rather just being. Lomography is a completely personal and free-form of photography, with the underlying philosophy being to go with the flow and to forget all the rules.

This method of photography is also well adapted to use with children as the care-free style retains the fun and excitement of taking photographs and thus keeps the child involved and interested in the research. The photographs can in some cases speak for themselves, and in others are a reliable prompt which serves as a method for eliciting a wealth of accurate information. The ten guidelines of Lomo photography will be provided to children, allowing them to capture the world around them unambiguously with no rules in order to obtain true images of what is important to them.

\subsection{Understanding the Context: Photo Elicitation}

While photography has considerable utility in its use to explore people's experiences and existences, this is particularly powerful where the photographs are embellished with explanations. Photo-elicitation, that is, the use of photographs as guides and stimulation in interviews, is considerably more effective than using speech or text alone [3]. The photographs are used as a prompt, with the photographs, and the narrative that they generate reflecting the cultural norms of the participant [19].

\subsubsection{Using Photographs to Explore Narrative}

Understanding photos involves three sets of questions, focused at content (what), purpose of creation (who, when, how) and interpretation (why). The photographs provide the stimulus and the motivation for the photographer to explain the photographs and identify what and why they took the photographs, a view which could be misinterpreted by analysing the images alone. Photo-elicitation is suitable for both children and adults, overcomes many issues associated with traditional methods, and generates a wealth of information. The "photographs can be communication bridges between strangers that can become pathways into unfamiliar, unforeseen environments and subjects" giving adults an unfamiliar journey into today's childhood [7]. Although photographs may elicit a narrative directly related to the images, they can be such a powerful stimulus for reflection that they will result in the description of experiences which are not directly related to that photograph [25]. Further, photo-elicitation can also motivate participants to provide an entire perspective of action, explaining and creating 'back-story' based on their views and experiences as stimulated by the photograph [19].

\subsubsection{Photo-Elicitation Approaches}

Photo-elicitation has three main approaches: auto driving, reflexive photography and photo voice. The three variations are all similar in their technique with photos used as stimulus to gather a deep understanding of the interviewee. Autodriving involves the use of photos taken by the interviewees themselves, with the interviewee then 'driving' the interview, discussing the photos they have taken and/or are viewing. Similar to autodriving, reflexive photography [32] involves photographs taken by interviewees who then submit themselves to a reflexive interview in which they react to and reflect upon the deeper meanings of their own created photographs. Photo Voice or Photo Novella [12], involves interviewees creating 'picture stories', taking photographs that portray everyday existence and then discussing their significance and meaning with an interviewer.

\subsubsection{Experiences with Photo-Elicitation}

So far, the use of photo-elicitation techniques has overall provided a positive appearance as a highly effective, useful and reliable method for use in research. This is confirmed by Heisley and Levy [19] as "autodriving provides a type of member check to increase the credibility of the researcher's interpretation" and "makes it possible for people to communicate about themselves more fully and more subtly and, perhaps, to represent themselves more fairly". Zambon [45] adds that "it [photo elicitation] removes the problem of researcher bias, as it is the participants who take the images used in the interviews". Photo elicitation contributes to gathering richer data about similar topics and offers a closer look at what and who participants consider important [30].

\subsubsection{Photo-Elicitation and Children}

Although photo elicitation has been mainly used with adults, there are some studies that have involved children. Labbo et al. [27] researched the use of a digital camera produced images to inspire children to tell a story to improve literacy. It was found that the photos served as a memory link to a child's experiences (including those experiences that occurred over time). Labbo et al. [27] also found that digital photos provided tangible prompts for descriptive language. Banister and Booth [2] used photo elicitation to evaluate how children develop likes and dislikes towards products, finding that this method provided a more positive and useful response than other approaches such as ethnographic observations, drawing activities and interviews. They found that the photographs provided a huge insight into the lives of the children, as did Rasmussen [36], who used photo-elicitation to understand children's views of place. The study allowed the children to take photographs of places they enjoyed spending time, which showed that children relate not only to official places provided by adults, but also to informal places, often unnoticed by adults.

Photo-elicitation also readily allows for adaptation for use with specific user groups and purposes. Clark-Ibáňez [6] created the child-centric Photo-Elicitation Interview (PEI) and found that 
this resulted in considerable engagement from the interviewees. In the classroom situation, [38] asked the students to make a poster from the photographs, adding captions and using it to present the positives and negatives of their school. This additional practical use of the photographs produced additional information to that in the discussions of the photographs and increased clarity about children's preferences.

\subsubsection{Rationale for Use of Photo-Elicitation with Children}

There is a considerable increase in information received in an interview led by photography [45], with photographs resulting in tangential and unexpected conversations frequently leading to useful information that would not have emerged in a traditional interview. However, our decision to use photographs was based not only on their potential to increase the information gathered within an interview but additionally because photography and the use of photographs is particularly appropriate for early design stage activities with children. The photographs provide a focal point, rather than the child themselves and can aid in dropping the boundaries between interviewer and interviewee [3]. This can reduce the power imbalance between the interviewer and the child, facilitating communication, lessening awkwardness and anxieties, and can ease rapport [6]. Further, if the child has themselves taken the photograph they also have guaranteed awareness and knowledge about the photo, thus contributing to their sense of comfort in the later discussion of the photos.

The use of self photographs supports the child in better expressing their point, provides them with a subject to talk about, and ensures that have knowledge of the 'story' behind the photograph. Further, the photographs aid the children in expressing themselves and entice them to offer information, with photo-elicitation encouraging participants to verbally reflect on their views and perspectives.

\subsubsection{Practical Considerations}

Whilst lomography and photo-elicitation appear to offer considerable benefits to the researcher or analyst, [6] highlights some possible issues, including the financial cost, coordination of camera dissemination and retrieval, and the time spent developing the photographs and conducting the interview. Like other techniques where a considerable amount of diverse information is collected about the user, the researcher must by necessity sift through the results from individual interviews and group activities to identify key issues and factors that respond to the researcher's current issue [34]. Only through the researcher compilation can the collected information from the elicitation exercise be developed into a meaningful result.

There are considerable benefits of the interviewee taking the photographs, as Radley and Taylor [35] note, in such situations, the photographs "provide a direct entry into their point of view". However, using photography for participatory design with children raises a number of practical considerations. These include camera loss, lack of skill in photography [6]; technical limitations of cameras producing poor image composition and quality [30]; and use of the camera in inappropriate ways (also seen with other device use). Further, although most children willingly engage with photography, some may be prevented through peer relationships and/or family dynamics to create photographs either within certain contexts or completely.

Meo [30] found that photo-led interviews with self-photography expensive, time consuming, difficult to manage the interviews and complicated organising the storage of the material post fieldwork, further she identified that this kind of interview was more challenging and demanding. Ellis [11] also challenges previous statements that the inclusion of photography diminished boundaries and argues that self-directed photography and its outputs are a highly problematic technique to implement, interpret and use for the researcher, as well as causing anxiety for the researched. Also, contradicting previous statements that the photographs add more diverse topics, content and information to the interviews, Meo [30] found in some cases that this was not always true and that with some interviewees, particularly those who believed that the photographs should 'speak for themselves,' the interviews may in fact suffer due to the inclusion of photographs instead of benefiting.

While there are clearly pragmatic considerations in the use of photo-elicitation and lomo photography with children, the benefits in terms of engagement with the user group and clearer identification of user requirements with the water-safety product outweighed these considerations. Further the chosen approach was both innovative and exploratory and in keeping with a broader context of the design of empathic applications for children where user participation was critical.

\subsection{Matching Context: Classroom-Based Use}

The proposed water safety application for 11 to 13 year olds was commissioned to fill a gap in current provision, with children up to the age of 11 currently receiving annual workshop interventions delivered by the Local Authority and water safety experts in a classroom context. While the proposed application is intended to replace this annual 'Water Safety Roadshow' - the application itself is being co-designed for delivery in a classroom context. The classroom context is therefore relevant both as the expected point of delivery of the application and the context in which user participatory research would be undertaken.

The importance of co-design of multimedia learning applications with their context of delivery is well understood. Indeed, in the evaluation of computer aided learning applications it has been stressed that it is not technology alone which causes learning and that realistically evaluation needs to measure the combined effect of an "ensemble of factors" from the context of delivery.

However, there are considerable difficulties in creating participatory methods that support design and development activity within the classroom context [37] and [39]. Apart from ensuring that learning takes place there are a number of constraints related not only to technology but additionally to providing an appropriate learning experience that matches classroom practice and curricular expectations. Creating a classroom based method must incorporate the 'whole system,' providing benefits not only for the design process but also for those involved with this process.

\subsubsection{Group Working}

Within the classroom situation, considerable work can occur in small groups, with teaching at the group level encouraged by the DFES and implemented within national strategies for Key Stage 2 and Key Stage 3 (initially being promoted as best practice in the National Literacy Strategy - independently and with another adult or teacher). Group work, as a best practice is continuing to be exemplified by the DFES [9] as a means of supporting mixed ability groups. There are considerable benefits for children when working in homogeneous groups including increased confidence and educational attainment; 
improved classroom behaviour; and an increase in active engagement in learning [22].

As our aim is to create methods and techniques that can be used in the classroom and that meet National Curriculum requirements, teachers have identified that any such methods must include a considerable element of group as well as individual activity. Although there have been some photoelicitation approaches that incorporate group activities, most approaches to photo elicitation are individual. Indeed, ClarkIbáňez [6] identifies that individual's perspectives may be lost or diminished if photographs are viewed in a group setting. However, not only can an individual interview be intimidating for some children (especially when conducted with a stranger) but it is an approach that removes the child from the classroom and the activities of their cohort. Although there has been very limited work with photo-elicitation in the classroom, Schratz and Steiner-Loffler [38] used group photo-elicitation approaches to engage students of mixed ability in a structured learning task and allowed for inclusion of their interests

Although photo elicitation has typically been individual, Prosser [34] recognizes potential benefits of group-based activities, particularly when: the setting gives everybody a fair chance to participate; the group activity is appropriate to children's age and educational level and decision making and activities in the group are supported with communication skills and conflict management. Further, Parker [32] adds that collaborative photography can simultaneously deliver several outcomes: providing novel information for the researcher, emancipating and empowering interviewees to provide divergent accounts of the same material. This is extremely applicable to children and offers a key view into their perceptions of their 'world.'

Our focus is using photo elicitation for gaining child input into the early lifecycle of an educational product. Earlier research $[14,15,43]$ has highlighted the benefits of group working with children in the early design lifecycle. Similarly, we [16] have used a variety of small group techniques and found that they stimulate discussion, even if relating to sensitive subjects such as bullying. In this approach, following teacher advice, we have based groupings on friendship aiming to stimulate constructive peer-review [9].

\subsubsection{Adapted Photo-Elicitation Approach}

The photo elicitation, similar to the research conducted by [38], will include a group analysis activity of the produced photographs. Working in small groups within the classroom will add to the ecological validity of the experience and will ensure that children feel at ease. The group activity will analyse the photographs, pin pointing key images and categories which are important to children in order to inspire the design of the multimedia.

\section{METHOD}

Our approach to gaining early design requirements and inspiration was the use of Lomography and an adapted photoelicitation method for use with a small group of children within the classroom. The aim of this activity was to gain an insight into the things that children like and are attracted to so that this information could be transferred into the presentation and possibly interaction design of a multimedia application to make it more well suited, usable and appealing for the target age range.

The study group comprised 10 children ( 5 girls, 5 boys) of year 7 (11-12). The children were recruited on a voluntary basis after an explanation of the research study. They were told that they would each be provided with a disposable camera and that they would be required to take photographs of anything they liked and things that caught their attention, wherever they were, over the period of a school week.

The 10 disposable cameras were given to the children in the study by their teacher on a Monday morning and were collected on Friday afternoon. All 10 children completed the lomo photography element of the research and returned the cameras on time. The photographs were developed and then reviewed to ensure that the cameras had not been misused and to gauge whether or not the group categorisation activity could take place within the school context with the photographs from the Lomography. At a later date, after the photographs had been developed, the children were split into two groups and received their photographs back. The children then worked in these groups to sort the photographs into categories of their choosing and to discuss their approach and the photographs that were taken. Care was taken to make sure that the categorisation was that of the children's and not influenced by the supervisors. The children felt surprisingly willing to discuss the photographs while the supervisors noted their comments. The children seemed to view the categorisation as the "activity" and felt no pressure to provide background information about the images.

The group activity used the photographs that the children had taken independently, to work collaboratively to analyse, arrange, and sort the images into categories of their choosing. The school provided an empty classroom for the exercise and one hour with the children during form room time to prevent any disruption of their normal timetable.

On the day of the exercise, after having all ten packs of photographs developed, the children were collected from the form class and brought to the classroom allocated. Seven out of the ten children were in attendance on the day of the group categorisation, five boys and two girls. The children naturally split into two groups when situated in the room, with four boys in one group and two girls and 1 boy in the other. Both groups were given their own packs of photographs, plus 1 extra pack to the group of boys, which had a missing member, and 2 extra packs to the mixed group for the missing members.

The children were asked to look at all the photographs within their group, and arrange them into categories on large sheets of paper; they were also asked to name these categories together. They were additionally told that they could disregard any photographs that they didn't want to categorise either because they regretted taking them or could not tell what the photograph was about. They were then asked to pick as a group their favourite images from each category and give reasons for the choices they made. Each of the groups worked with a researcher, who made notes and guided when necessary.

The children started by looking through their own photographs, then those of each other, including the spare packs of those not present. They were then given large sheets of paper, glue and pens to arrange and organise the photographs onto the sheets. After completing this activity they were then asked to make a second review of the categorised photographs to ensure that their categories adequately reflected group member wishes, and to modify their categorisations if necessary.

\section{RESULTS AND INTERPRETATION}

The initial review of the photographs identified that some of the children had obviously had technical difficulties with the use of disposable cameras. Some packs contained few images as the photographs could not be processed and some photographs 
were dark and unclear as the flash had not been used indoors. However, many photographs were still usable, and those packs with few photographs balanced out those which were full.

A quick review of the photographs identified a dominance of the following images:

- Technology: such as mobile phones, CD players, computers and televisions.

- Animals and pets: such as dogs, cats, hamsters, fish and horses.

- Outdoor scenery images: predominantly at South Shields beach, on the grassy area the Leas, also with outdoor items such as bikes.

- People: featured in many of the photographs, with pictures taken of friends, school, out of school activities and family.

The group categorisation activity worked well, with all children engaging with the process and readily discussing what their own photographs represented and what they thought that the photographs of others represented. Considerable care was taken not to lead the children's activities or discussion at this stage For example, when children asked for examples of categories, researchers gave vague examples such as clouds or the ground, as there were few photographs which could be categorised like this. The children readily thought up their own categories with considerable creativity and imagination. The second review allowed the children to check that they all agreed with the categories, and resulted in some photographs being re-assigned and some not included.

Time constraints meant that the activity was very focused, with the researchers spurring the children on and keeping the exercise on track. An hour was insufficient for this exercise, with the final activity of children marking their favourite images rushed and not completed fully.

The observations of the children categorising the images identified that they worked well together. There was appropriate turn taking in dialogue and sharing in the practical activity. All of the children engaged in the activities and discussion. Both groups seemed naturally to decide the categories together and compiled the photographs efficiently. Each individual provided arguments and reasoning when adding a photograph to the category, and children's individual categorisations were largely accepted by the other members of the group. The children continued to have fun throughout the activity, writing funny comments and laughing at certain photographs, demonstrating their enjoyment in the activity. They also provided emotional and personal information about what the photographs meant to them, with both groups annotating the images without being prompted to do so.

The categories created by the groups were as follows:

- Group 1 (mixed): local coastline, objects, pets, people.

- Group 2 (all male): games, cars, houses, family, life in school, views, pets, dance club.

Although Group 2 produced more categories, many of these were very people focused (dance club, life in school, and family) and the amount of people captured in photographs was similar in both groups. Group 1's people category was very large, featuring school group photographs and singular photographs from an award ceremony as well as shots with a well-known local entertainer. Group 2's categories also contained many group shots of friends and family members.
For the 11-13 year olds in this study, people, such as friends, family and those in professional roles are clearly an important factor in their lives. The pet category featured in both groups, with Group 1 having an extensive pets section which mostly featured a large fish pond. Group 2's pet category featured pets such as dogs, cats and hamsters.

Outdoors was another predominant theme in categories such as views and the Leas, which is the local coastline; both groups featured the coastline and greenery. The application to be developed was for water safety, however, the children did not know this, yet surprisingly (or perhaps not) there were a lot of photographs about water, which demonstrates children's attraction to the open water environments in their immediate locale. For example, there were many photographs of the South Shields beach area, just south of the Tyne estuary. Also featured were photographs of large public fountains and many images of a fish pond.

Group 1 compiled many things into a vague objects category such as electrical items, personal belongings and outdoor items such as bikes. Group 2 had a limited games section, depicting a games console and some toys. These categories both featured fun and entertainment items such as electrical equipment including games consoles, computers, TVs and mobile phones, and items such as wrestling figures, keyboards and DVDs.

When asked to choose favourite images from each category, in the people category, the children selected images of people they liked or of pictures of people that they found amusing. In other categories, photos that were selected included a keyboard by Group 1, and a games console by Group 2, demonstrating that entertaining, fun objects are also important to children of this age group.

Both groups had outdoor categories (local coastline and views). Both groups selected a photograph of the same place, the Leas at South Shields beach, a place that the children like to play. In both groups, comments were made about how 'lovely' the photos of the water were. This selection further reinforces that children are drawn to water environments, enjoy and play around water and find it interesting.

The children commented that they enjoyed taking the photographs as they have had little experience of owning their own camera, and liked how they could take photographs of anything they wanted.

Overall the photo-elicitation exercise demonstrated that although there were two separate groups of children's, the categories in both groups had very similar themes such as people, entertainment, animals and the outdoors, especially water environments.

\section{DESIGN INSPIRATION}

Initial design ideas on paper were based on brainstorming with stakeholders and competitive analysis of applications and websites aimed at water and other forms of safety. This resulted in the tentative creation of water themed cartoon characters (a water droplet) which would give instructions and provide an animated story of a child rowing a boat on a lake and getting into difficulties. In addition, a scenario of water dangers was provided that had been used previously within a water safety roadshow and adapted for multimedia delivery; this included a 'spot the dangers' activity.

\subsection{Design Adaptations}

The photo-elicitation study found corresponding themes in the photograph categories between the two different groups. These 
were entertainment, people, animals and the outdoors, especially water environments. These common themes which children highlighted attracted their attention, and were subsequently incorporated into the design of the multimedia application on water safety. By incorporating the kinds of images that children themselves had been attracted to when taking pictures with their own disposable camera, the intention was to use these 'attractors' to make the application more appealing and attention grabbing for children of the same age. Clearly, visual-content output of the Lomography process would require further assimilation into design, from both a technical and aesthetic point of view, but by incorporating these visuals the aim was to develop a learning application which was more likely to achieve its educational goals.

As discussed previously, the photographs taken by the children contained many images of the coastal area. Although the River Tyne is equally as accessible as the coastal area to these children, the application subsequently focused on coastal dangers in particular - because it was to these locations that children seemed to gravitate. This high number of coastal photographs provided by the children also led to the decision to use cartoon representations of favourite local water environments and landmarks, helping children to contextualize water safety and increase the association of dangers with the local area. This included changing initial storyboard designs built around the narrative of a child rowing a boat on a lake and getting into difficulty, to a beach environment using an inflatable boat, a more familiar context for local children.

The 'spot the dangers' activity which was also built into early conceptual designs, aimed to contextualise the user, and was adapted to give the application a local approach - to help children relate to the dangers present in their own environment. This now uses South Shields groyne, a highly recognisable landmark throughout the region, with particular safety issues including rip currents, high waves and fast incoming tides.

However, the photo-elicitation exercise showed the importance of people to children; therefore human characters are proposed for the application in place of the water-themed cartoons, as children have showed a great interest and emphasis on people in the research conducted. This has resulted in the construction of cartoon human characters of children, adults and lifeguards to support the user through activities, games and story scenarios.

From the photo-elicitation study, it could be seen that children were more attracted and interested in other children, especially groups of children. Although adults did feature, these tended to be family or adults with a specific professional role that the children understood. In the application, we have used primarily groups of child characters, with small groups involved in the 'spot the dangers' section and within a scenario, where children related the risks and dangers of water to themselves. A lifeguard character is also being developed, to ask the questions after the scenario story animation as children will recognise the character as a professional and will take the questions seriously.

The children's fascination with water led to a design based on ideas inspired through the photographs. This included floating bubbles which pop when the user clicks on them, fish which follow the mouse, and ripple effects when the mouse is clicked - as inspired by photographs produced by the children. Group 1 's pet category especially concentrated on the large fish pond located at the school. These images have inspired the application menu system, which is depicted as a pond where children catch the fish to select the menu option, with the fish swimming across the screen and under the water, each becoming a menu item in turn when their heads pop up (see Figure 2).

Many of the photographs taken of water show a lot of movement, such as waves which splash and crash and water in fountains. Other photographs also show a much more gentle calming movement of water such as the sea, with both dramatic and calm movement of water attracting children's attention. These photographs have inspired the design to incorporate movement to keep the children's attention throughout the application. Interactive areas such as the 'spot the danger' and scenario areas already have movement; however, the information and main menu will also have movement of water with the aim of engaging the user.

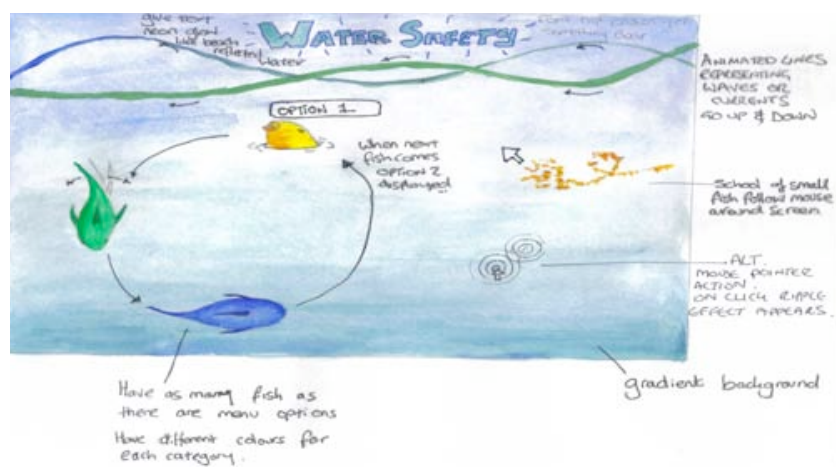

Figure 2. Inspiration for interface design.

The photographs marked as favourites by the children, and their discussions of photographs such as the keyboard and games consoles, show that children like to interact with objects in a fun way. Children want interactive activities to engage their interest. This has been reflected in the design through image maps on spotting dangers, interactive scenarios, and a fun, light-hearted quiz.

The results from the photo-elicitation and the design inspiration that they had led to were discussed with the sponsor, demonstrating how the photographs had influenced the design. The sponsor reacted very positively to the proposed design, discarding their own previous ideas in favour of a design inspired by the children's visual representations of their world. Most notably, they abandoned the ideas for an animated water character (for which designs had already been created) convinced by the photo-elicitation that children might respond better to children and other-people characters being used within the application.

\section{DISCUSSION}

Photo-elicitation typically involves interviews where participants talk about the photographs being shown and share their 'stories', potentially providing more information than that of a normal question-and-answer interview. Here, an alternative approach was taken, where the analysis of the photographs did not rely on a one-to-one interview method to elicit information, but instead used a practical, group exercise to categorise the photographs and provide discussion on their contents. This method was particularly well suited to working with children and provided an engaging, fun, non-intrusive activity.

Lomography allowed the children to take photographs in a carefree, spontaneous way. It supported the aim of capturing images of anything that participants found interesting or that caught their attention, and was an ideal input to photo-elicitation as it permitted and, indeed, required un-posed, unarranged and 
unplanned photographs to be truly effective. Lomo photography fitted in well with children's usage of cameras as fun, spontaneous toy-items and allowed a care-free, no-rules approach to be applied to the photography exercise, thus supporting individual, fun activity.

The group categorisation activity that we have developed in collaboration with educationalists provides a novel technique for photo elicitation, moving away from the focus on individuals and the use of interviews as seen in autodriving, photo voice, and reflexive photography. This approach and the time frame seem particularly apt for children, keeping the activity fun and engaging as well as quick and non-disruptive.

The group approach taken was found to be highly effective and shows the benefits of groupings based on friendship for this type of practical and social activity. The group method kept the research fun and participatory, it reduced the level of anxiety of the children, allowing them to work within familiar groups in a school-like activity, so that they felt comfortable, worked efficiently, and had fun whilst producing insight into their lives.

Through allowing the two groups to sort their photographs into their own categories, this allowed common themes between the two separate group's categories to be found, achieving a deeper understanding of the target audience. The categories did show similarities, and through this method those themes were able to be translated into design requirements targeted as the things which 11-13 year olds are drawn to. Within the group activity there were some unexpected insights into the personal emotions of the children as they, without direction, annotated their photographs, providing more information on their interests.

This adapted methodology was particularly successful with the children as they found the photography exercises enjoyable, took the research seriously throughout, and many useful photographs and categories resulted. This participatory method overcomes some of the challenges associated with gaining children's views and perspectives. It ensures that the child feels empowered and that they are leading the activity, thus reducing the power imbalance and focusing the attention onto the photographs rather than the child themselves. The photographs help stimulate and focus discussion, with the hands-on activities promoting participation.

This approach helps to ensure that in application development, that the content is developed for, and targeted at, the right age group. With any method aimed at classroom use, it is essential that the material and activities provide an appropriate level of challenge with pedagogical stimulation and curricular relevance. This Lomographic photo-elicitation approach supports a range of National Curriculum learning objectives, both in the general framework (e.g., English Speaking and Listening strand), in which the group activity encourages discussion and interaction, along with images having been proven a useful tool within education for a variety of reasons, in that images are a stimulus for learning in many ways, such as prompting discussion and reflection, and for specific subjects, such as Art and Design. Lomogaphic photo-elicitation provides an imaginative starting point and aids in meeting requirements from the National Curriculum. For example, in "Exploring and developing ideas" pupils need to be taught to "record and analyse first-hand observations, to select from experience and imagination and to explore ideas for different purposes and audiences" and to "organise and present this information in different ways." Lomographic photo-elicitation provides a novel visual technique ideal for this purpose. In "Investigating and making art, craft and design" the National Curriculum identifies that children should be taught to "experiment with and select methods and approaches, synthesise observations, ideas and feelings, and design and make images and artifacts." Through incorporating a group activity within a classroom situation, we can use the Lomography and photo-elicitation to support this learning outcome.

Technical and social context can be considered through exploring the history of the Lomographic style of photography. The group categorisation activity provides a supportive, collaborative starting point upon which students can develop initial ideas and concepts based upon their chosen photographic groups. Coverage of some National Curriculum objectives in the Art and Design Curriculum at Key Stage 3 can be achieved using our approach, and further, it can be used within schemes of work produced by the QCA (Qualification and Curriculum Authority) as a means of investigation. The QCA provide an example unit for work with Year 9 on "Personal places, public spaces", in which children are asked to work individually to collect inspiration through a range of activities including photography. This is followed by a collaborative activity in which it is suggested they create a $3 \mathrm{D}$ art object for display in a public space. As can be seen, the approach outlined here could provide considerable input to this learning outcome, encouraging a teacher to participate in the design of new software, knowing that in doing so the children will also be contributing to their National Curriculum learning objectives.

Ultimately the use of novel photo-elicitation techniques with children benefited the design process greatly as the methodology allowed children to share their perspectives through a fun and engaging activity, such prosperous results would be unlikely using more traditional methods. The resulting application has had positive responses and will be developed into a full multimedia application for use within secondary schools in the local area later this year.

\section{CONCLUSIONS}

Lomography / photo elicitation offers HCI designers an important insight into the everyday existence of users. Less arduous than cultural probes, and less invasive than observation and recording, lomography offers users an enjoyable, rapid approach to providing designers with a recorded access to daily life awareness.

\section{ACKNOWLEDGMENTS}

This work was partially supported by European Community (EC) and is currently funded by the eCIRCUS project IST-4027656-STP. The authors are solely responsible for the content of this publication. It does not represent the opinion of the EC, and the EC is not responsible for any use that might be made of data appearing therein.

\section{REFERENCES}

[1] Alexandersson, M. Fotografering som bera"ttelser om livet [Photography as a narrative about life]. Presented at The International Photo Exhibition, Goteborg, Sweden, 1997.

[2] Banister, E. N., and Booth, G. J. Exploring innovative methodologies for child-centric consumer research. Qualitative Market Research: An International Journal, 8 (2005), 157.

[3] Carlsson, B. Depicting experiences. Scandinavian Journal of Educational Research, 45 (2001), 125-143.

[4] Carter, S., and Mankoff, J. When participants do the capturing: The role of media in diary studies. In Proceedings of the SIGCHI conference on Human factors 
in computing systems (CHI 2005). ACM Press, New York, NY, 2005, 899-908.

[5] Christensen, P., and James, A. Research with Children: Perspectives and Practices. Falmer Press, London, UK, 2000.

[6] Clark-Ibánez, M. Framing the social world with photoelicitation interviews. American Behavioural Scientist, 47 (2004), 1507-1527.

[7] Collier, J., and Collier, M. Visual Anthropology: Photography as a Research Method. University of New Mexico Press, 1986.

[8] Crabtree, A., Hemmings, T., Rodden, T., Cheverst, K., Clarke, K., Dewsbury, G., Hughes, J., and Rouncefield, M. Designing with care: Adapting cultural probes to inform design in sensitive settings. In Proceedings of $\mathrm{Oz} \mathrm{CHI}$ 2003, New directions in interaction: Information environments, media \& technology. (Brisbane, Australia, 2003). 2003.

[9] DFES. Best Practice: Teaching Non-Fiction to Children with Severe Learning Difficulties. 2003.

[10] Druin, A., Bederson, B., Boltman, A., Miura, A., KnottsCallahan, D., and Platt, M. Children as our technology design partners. In A. Druin (ed.), The design of children's technology. Morgan Kaufmann, San Francisco, CA, 1999, 51-72.

[11] Ellis, R.. Picture Imperfect? The Cultural Politics, Interpretation and Anxieties of Self-Directed Photography Picturing the Home Space. Chimera Working Paper, 2003.

[12] Frohmann, L. The framing safety project: Photographs and narratives by battered women. Violence Against Women, 11, 11 (2005), 1396-1419.

[13] Gaver, W., and Dunne, A. Projected realities: Conceptual design for cultural effect. In Proceedings of the SIGCHI conference on Human factors in computing systems (CHI 1999). ACM Press, New York, NY, 1999, 600-607.

[14] Gibson, L., Newall, F., and Gregor, P. Developing a Web Authoring Tool that Promotes Accessibility in Children's Designs. Presented at the conference on Interaction design and children, Preston, UK, 2003.

[15] Guha, M., Druin, A., Chipman, G., Fails, J. A., Simms, S., and Farber, A. Mixing Ideas: A New Technique for Working with Young Children as Design Partners. Presented at the conference on Interaction design with children, Maryland, USA, 2004.

[16] Hall, L., Woods, S., and Dautenhahn, K. FearNot! Designing in the classroom. In Volume 2 proceedings of the BCS HCI Conference 2004. (Leeds, UK, 2004). 2004.

[17] Hall, L., Woods, S., Dautenhahn, K., and Sobreperez, P. Using Storyboards to Guide Virtual World Design. In Presented at the conference on Interaction design with children, Maryland, USA, 2004.

[18] Harper, D. Talking about pictures: A case for photo elicitation. Visual Studies, 17 (2002), 13-26.

[19] Heisley, D. D., and Levy, S. J. Autodriving: A photoelicitation technique. Journal of Consumer Research, 18, (1991), 257.

[20] House, N. A. V. Flickr and public image sharing: Distant closeness and photo exhibition. In CHI 2007: Extended abstracts of the SIGCHI conference on Human factors in computing systems. ACM Press, New York, NY, 2007, 2717-2722.
[21] Hurworth, R. Photo-interviewing for research. Social Research Update, 40 (2003), 1-7.

[22] James, M., and Pollard, A. Improving Teaching and Learning in Schools: A Commentary by the Teaching and Learning Research Programme. 2006.

[23] Kam, M., Ramachandran, D., Raghavan, A., Chiu, J., Sahni, U., and Canny, J. Practical considerations for participatory design with rural school children in underdeveloped regions: Early reflections from the field. In Proceedings of the 2006 conference on Interaction design and children. ACM Press, New York, NY, 2006, 25-32.

[24] Kanstrup, A. M. Picture the practice: Using photography to explore use of technology within teachers work practices. Forum Qualitative Sozialforschung / Forum: Qualitative Social Research [On-line Journal], 2002.

[25] Kaplan, S., and Lewis, I. Students' Perspectives of Health and Safety in Schools. EENET and the University of Manchester, UK, 2005.

[26] Kindberg, T., Spasojevic, M., Fleck, R., and Sellen, A. "I saw this and thought of you": Some social uses of camera phones. In CHI 2005: Extended abstracts of the SIGCHI conference on Human factors in computing systems. ACM Press, New York, NY, 2005, 1545-1548.

[27] Labbo, L. D., Eakle, A. J., and Montero, M. K. Digital language experience approach: Using digital photographs and software as a language experience approach innovation. Reading Online (2003), 24-43.

[28] Lewis, A., and Lindsay, G. Researching Children's Perspectives. Open University Press, Milton Keynes, UK, 1999.

[29] Makela, A., Giller, V., Tscheligi, M., and Sefelin, R. Joking, storytelling, art-sharing, expressing affection. In Proceedings of the SIGCHI conference on Human factors in computing systems (CHI 2000). ACM Press, New York, NY, 2000, 548-555.

[30] Meo, A. Taking Photographs to Make Sense of the World? The Advantages, Limitations and Challenges of the Use of Photographs in a Qualitative Study in the City of Buenos Aires (Argentina). Presented at the Ethnography Conference, Oxford, UK, 2005.

[31] Pardo, S., Vetere, F., and Howard, S. Broadening stakeholder involvement in UCD: Designers' perspectives on child-centred design. In Proceedings of the 19th conference of the computer-human interaction special interest group (CHISIG) of Australia on Computer-human interaction. CHISIG of Australia, Narrabundah, Australia, 2005, 21-25.

[32] Parker, L. D. Photo-elicitation: An ethno-historical accounting and management research prospect. Critical Management Studies (2005).

[33] Plaisant, C., Clamage, A., Hutchinson, H. B., Bederson, B. B., and Druin, A. Shared family calendars: Promoting symmetry and accessibility. ACM Transactions on Computer-Human Interaction, 13, 3 (2006), 313-346.

[34] Prosser, J. Image-Based Research: A Sourcebook for qualitative researchers. Routledge, Falmer, UK, 1997.

[35] Radley, A., and Taylor, D. Images of recovery: A photoelicitation study on the hospital ward. Qualitative Health Research, 1, 13 (2003), 77-99. 
[36] Rasmussen, K. Places for children, children's places. Childhood, 11 (2004), 155-173.

[37] Rode, J. A., Stringer, M., Toye, E. F., Simpson, A. R., and Blackwell, A. F. Curriculum-Focused Design. Presented at IDC 2003. 2003.

[38] Schratz, M., and Steiner-Loffler, U. Pupils using photographs in school self-evaluation. Image-Based Research: A Sourcebook for Qualitative Researchers, 1, (1998), 235-251.

[39] Smith, B. K., and Reiser, B. J. National Geographic unplugged: Classroom-centered design of interactive nature films. In Proceedings of the SIGCHI conference on Human factors in computing systems (CHI 1998). ACM Press, New York, NY, 1998, 424-431.

[40] Sorbring, E. Girl's and Boy's Views of Conflicts with Parents. Department of Psychology, Göteborg University, Sweden, 2005.

[41] Tuck Wah, L. Randomness as a Resource for Design. 2006.
[42] Tunstall, S., Tapsell, S., and House, M. Children's perceptions of river landscapes and play: What children's photographs reveal. Landscape Research, 29 (2004), 181

[43] Verhaegh, J., Soute, I., Kessels, A., and Markopoulos, P. On the Design of Camelot, An Outdoor Game for Children. Presented at the conference on Interaction design with children, Tampere, Finland, 2006.

[44] Voida, V., and Mynatt, E. D. Conveying user values between families and designers. In CHI 2005: Extended abstracts of the SIGCHI conference on Human factors in computing systems. ACM Press, New York, NY, 2005, 2013-2016.

[45] Zambon, M. J. Confessions of a qualitative researcher: Reflexive photography and the exhibition of culture in schools. Educational Perspectives, Journal of the College of Education, 37 (2005), 38. 